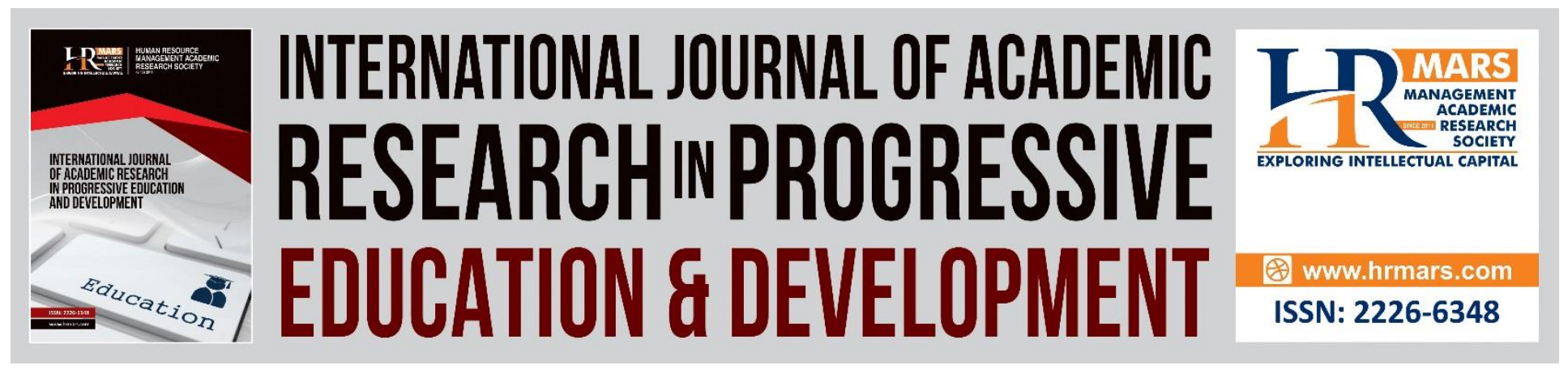

\title{
Cloud Computing: Things to consider by Information Professionals (IP)
}

Saiful Farik Mat Yatin, Muhammad Naim Alias, Norazuwin Awang, Nur Faiqah Burhanud-din

To Link this Article: http://dx.doi.org/10.6007/IJARPED/v7-i3/4352

DOI: $10.6007 /$ IJARPED/v7-i3/4352

Received: 03 June 2018, Revised: 21 June 2018, Accepted: 03 July 2018

Published Online: 21 July 2018

In-Text Citation: (Yatin, Alias, Awang, \& Burhanud-din, 2018)

To Cite this Article: Yatin, S. F. M., Alias, M. N., Awang, N., \& Burhanud-din, N. F. (2018). Cloud Computing: things to consider by Information Professionals (IP). International Journal of Academic Research in Progressive Education and Development, 7(3), 116-126.

Copyright: (c) 2018 The Author(s)

Published by Human Resource Management Academic Research Society (www.hrmars.com)

This article is published under the Creative Commons Attribution (CC BY 4.0) license. Anyone may reproduce, distribute, translate and create derivative works of this article (for both commercial and non-commercial purposes), subject to full attribution to the original publication and authors. The full terms of this license may be seen at: http://creativecommons.org/licences/by/4.0/legalcode

Vol. 7, No. 3, July 2018, Pg. 116 - 126

http://hrmars.com/index.php/pages/detail/IJARPED

JOURNAL HOMEPAGE

Full Terms \& Conditions of access and use can be found at http://hrmars.com/index.php/pages/detail/publication-ethics 


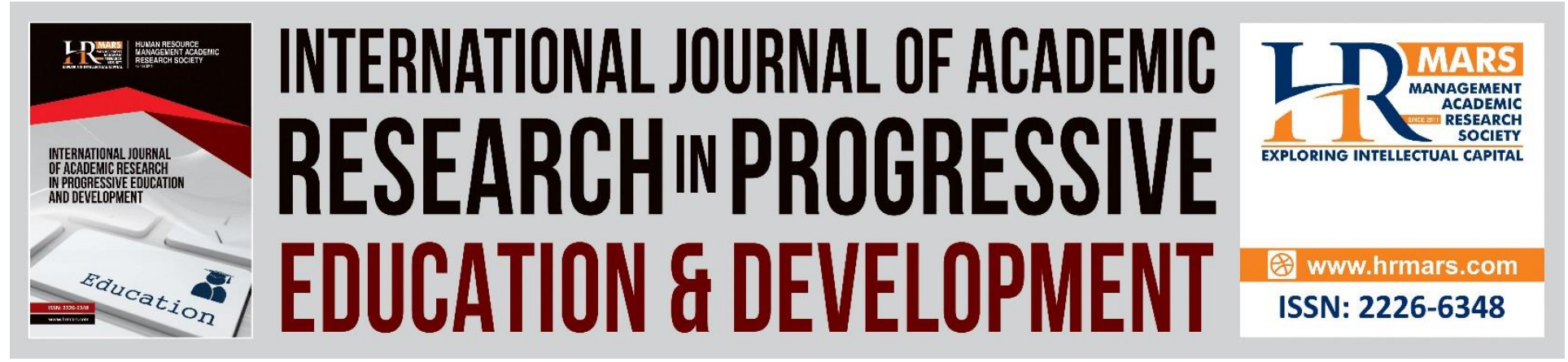

\title{
Cloud Computing: things to consider by Information Professionals (IP)
}

\author{
Saiful Farik Mat Yatin, Muhammad Naim Alias, Norazuwin \\ Awang, Nur Faiqah Burhanud-din \\ Faculty of Information Management, Puncak Perdana Campus, Universiti Teknologi MARA, \\ UiTM Selangor, Malaysia \\ Email: farik@salam.uitm.edu.my,wien2708@gmail.com
}

\begin{abstract}
Technology is fast growing and individuals are doing their best in order to catch up with this rapid growth. Those involved never failed to innovate and invent new technologies to be integrated with the current technologies. One of the innovations that technology has recently been presented is the phenomenon of cloud computing. Cloud computing provides almost all technological facilities needed in organizations at the cost of very less-skilled personal and computing devices. The essence of the concept of cloud computing is to provide end users with remote dynamic access to services, computing resources and applications which includes operating systems and infrastructure over the Internet. Cloud computing have three different service models which are Software as a Service (SaaS), Platform as a Service (PaaS) and Infrastructure as a Service (laaS). Cloud computing also has four different deployment models which are private cloud, community cloud, public cloud and hybrid cloud. Cloud computing could poses both opportunities and challenges for organizations and IP. An objective of this paper was to identify factors that could be consider for IP in adopting cloud computing.

Keywords: Cloud Computing, Adoption, Information Professionals, Information Management

\section{Introduction}

Public have yet to fully utilize the full potential of the traditional computing and now are already being introduced with cloud computing which is a program that runs and produce results in the window of a standard Web browser on a person's personal computer of which all of the applications and data needed for work are situated on a remote server on the internet. Severe market competition and business environment that changing dramatically, some businesses are starting to look for various state of the art information technologies to improve their business operations (Pan and Jang, 2008; Sultan, 2010) such as a new way for businesses to secure their big data. Cloud computing is the future for the development of computing technologies and it may become the next platform for building innovation ecosystem for the development of
\end{abstract}


Vol. 7, No. 3, July 2018, E-ISSN: 2226-6348 @ 2018 HRMARS

economic and social infrastructure (Armbrust et al., 2010; Ercan, 2010; Goscinski and Brock, 2010). One professional field that would have a lot of consideration on cloud computing will be the IP as they are involved in IM which consist of handling the storage, maintain, retrieve, organize and also preserve the information and records, and their "close connection to IT and because they may be serve as the gatekeepers to new technologies within the organization" (Aharony, 2014). Cloud computing could poses both opportunities and challenges for organizations and IP.

\section{Information Management}

Aharony (2011) stated that information management (IM) is a corporate responsibility that needs to be addressed and followed from the upper most senior levels of management to the front line worker. Organizations must be held and must hold its employees accountable to capture, manage, store, share, preserve and deliver information appropriately and responsibly. Part of that responsibility lies in training the organization to become familiar with the policies, processes, technologies and best practices in IM area. Meaning that, one of the requirements from IM role is 'store' which related to cloud computing that store the information into cloud.

Organizational structure must be capable of managing the information through the lifecycle as shown below in Figure 1, because information source format should be able to be distributed through multiple channels that may include smartphone and web interfaces.

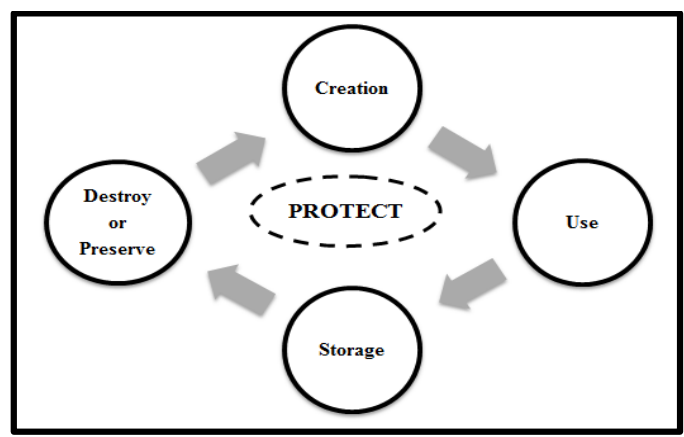

Figure 1: Lifecycle of Lifespan of Information Usefulness

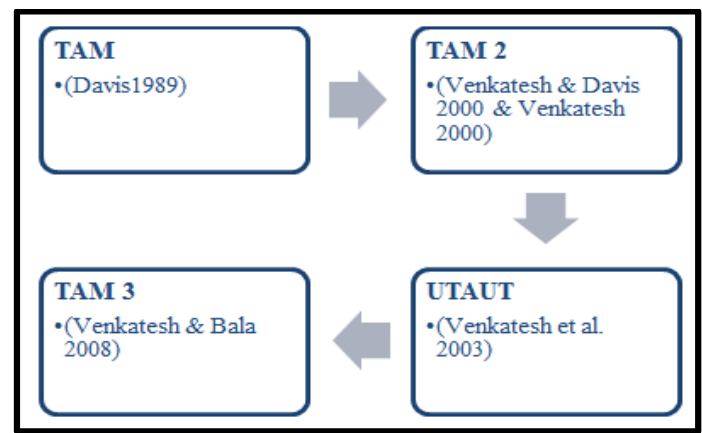

Figure 2: Development of TAM

Based on the Figure 1, information has a lifecycle of lifespan of usefulness consists of creation, use, storage, and destroy or preserve. For each stage of usefulness should deal with differently in order to efficiently maximize a business resource.

Creation - information life cycle begins when useful or relevant information arrives at or is created within an organization in a wide variety of formats using different equipment and technologies.

Use - information is transmitted to those who need it and, upon receipt, is used in the conduct of University business.

Store - information is filed or stored according to a classification scheme to permit quick retrieval, housed in a storage device, and protected and maintained to safeguard the integrity of the 
Vol. 7, No. 3, July 2018, E-ISSN: 2226-6348 @ 2018 HRMARS

information over time and viewed as either active or inactive. Destroy or preserve - important information need to be safely kept in order to use it for a long term as a references and evidence. Meanwhile, for the information that doesn't need to use, it can be destroy in order to make more space and reduce cost to keep the information.

One of the methods to keep and store information is through cloud computing and this is especially for the organization which manages a lot of information which is called big data. Besides that, when we discuss about storage, it means information that have live through their immediate use but still have value must be remain accessible such as administrative, fiscal, historical and legal values that are also called as inactive records.

\section{Information Professionals}

Information professionals (IP) are the person that responsible to strategically use the information resources in their organization, utilized and execute the mission of the organization. The main purpose of IP is to handle all IM task consists of handling the process of storage, maintaining, retrieve, preserve and organize the information and records. IP accomplish this feature through the development, deployment, and management of information resources and services. This statement is supported by Greer, Grover and Fowler (2007) which they also defined that IP is someone who collects, records, organizes, store, preserves, retrieves, and disseminates printed or digital information. Meaning that, IP is someone that responsible to store all information which related to adopt the cloud computing.

IP harness technology as a critical tool. IP are not limited to the librarians, knowledge managers, chief information officers ( $\mathrm{ClO}$ ), web developers and consultants. IP that work for information organization can be defined as those entities that deliver information-based solutions to a given market. Some commonly used names for these organizations include libraries, information centres, competitive intelligence units, intranet departments, knowledge resource centres, content management organizations, and others.

IP perform important tasks in the organization. They are most certainly play an important role as they are responsible in developing maintaining a portfolio of cost-effective, client-valued information services that are aligned with the strategic directions of the organization and client groups. They also tasked with building a dynamic collection of information resources based on a deep understanding of clients' information needs along with gathering evidence to support decisions about the development of new services and products. Responsible in maintaining current awareness of emerging technologies which is vital in the context of cloud computing, while assessing and communicating the value of the information organization, including information services, products and policies to senior management, key stakeholders and client groups and contributing effectively to senior management strategies and decisions regarding information applications, tools and technologies, and policies for the organization.

\section{Technology Adoption within the Organization}

Technology Acceptance Model or TAM has been developed by Davis (1989) is the most influential model that has been used by most of the researchers for understanding the acceptance of IT. This model suggests that when users are presented with a new technology, a number of factors influence their decision about how and when they will use it, thus, this model helps IP to understand about the adoption of new technologies (i.e. cloud computing). Aharony (2014) 
Vol. 7, No. 3, July 2018, E-ISSN: 2226-6348 @ 2018 HRMARS

stated that many studies of the adoption of new technologies such as cloud computing use TAM because it is easy to use and understand. In TAM, there are two factors that are relevant in computer use behaviours which are perceived usefulness and perceived ease of use. Aharony (2015) stated this theory explains individual behaviour towards technology that may influence IP adopting cloud computing in their workplaces. Davis (1989) defined perceived usefulness as the prospective user's subjective probability that using a specific application system will enhance his or her job or life performance. Perceive ease of use can be defined as the degree to which the prospective user expects the target system to be free of effort. TAM has been continuously been examined and upgraded from TAM, TAM version 2, Unified Theory of Acceptance and Use of Technology (UTAUT) and TAM version 3 as shown in Figure 2.

\section{Cloud Computing}

Cloud computing provides almost all technological facilities needed in organizations at the cost of very less-skilled personal and computing devices. UI Haq Quddusi (2014) defines cloud computing as the technology that uses the internet or network as central remote servers to maintain the data and applications where an installation is not necessary in order to use any applications and only require internet access to access their personal files. Buyya, Yeo and Venugopal (2008) defined it as "a type of parallel and distributed system consisting of a collection of interconnected and virtualised computers that are dynamically provisioned and present as one or more unified computing resources based on service-level agreements established through negotiation between service provider and customer".

\section{Key Characteristics of Cloud Computing}

There are several key characteristics that make cloud computing distinct to other information technology paradigm. According to the Mell and Grance (2011), there are five cloud computing's characteristics that is deemed essential.

\section{On-demand self-service}

With each service provider, the user can provision computing capabilities automatically without needing human interaction which means in-house IT skills is not a necessity to any project implementation.

\section{Broad network access}

The capabilities of the IT paradigm can be accessed over the network and through standard mechanisms that uses heterogeneous thin or thick client platforms which also can be termed as device and location independence (Farber, 2008).

\section{Resource pooling}

By utilizing a multi-tenant model along with vary virtual and physical resources that have been assigned and reassigned dynamically based on user's demand, it enables provider's computing resources to serve to multiple consumers where users would have no control or knowledge of the provider resource's whereabouts. 
Vol. 7, No. 3, July 2018, E-ISSN: 2226-6348 @ 2018 HRMARS

Rapid elasticity

In order to commensurate with user's expanding and contracting demand, cloud computing capabilities can be elastically modify to accommodate the demand. It uses dynamic resource provisioning in self-service basis in near real-time without relying for users to engineer for peak loads (Bruneo, Distefano, Longo, Puliafito, \& Scarpa, 2013; Mao \& Humphrey, 2012).

\section{Measured service}

Control and resource optimization according to the type of service provided is being managed by cloud systems as the performance is being monitored by IT experts hired by the service provider and web services constructing the consistent and loosely coupled architectures (He et al., 2014; Katsaros et al., 2012).

\section{Cloud Architecture}

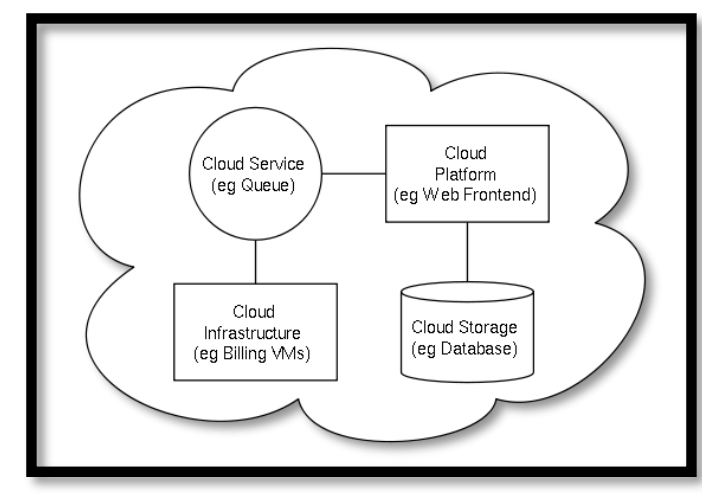

Figure 3 Cloud Architecture

The Cloud Computing Architecture of a cloud solution is the structure of the system, which comprises on-premise and cloud resources, services, middleware, and software components, geo-location, the externally visible properties of those, and the relationships between them. The term also refers to documentation of a system's cloud computing architecture. Documenting facilitates communication between stakeholders, documents early decisions about high-level design, and allows reuse of design components and patterns between projects. Besides that, other definition for cloud architecture is encompasses a variety of systems and technologies as well as service and deployment models, and business models. In the cloud architecture, there are having mix of three sub-architecture which is business architecture, technical and operational and it is important to have these sub-elements and their interfaces with each other to achieve the end objective and will complete the cloud architecture.

In this technology era, cloud computing became the major change that an organization want to adopted. Based on the Figure 3, cloud infrastructure refers to the hardware and software components, such as servers, storage, a network and virtualization software that are needed to support the computing requirements of a cloud computing model. A cloud service is any service made available to users on demand via the Internet from a cloud computing provider's servers as opposed to being provided from a company's own on-premises servers. Cloud services are designed to provide easy, scalable access to applications, resources and services, and are fully managed by a cloud services provider. Examples of cloud services include online data storage and 
Vol. 7, No. 3, July 2018, E-ISSN: 2226-6348 @ 2018 HRMARS

backup solutions, Web-based e-mail services, hosted office suites and document collaboration services, database processing, managed technical support services and more. As for cloud platform refers to the hardware and operating environment of a server in an Internet-based data center. Cloud storage is a cloud computing model in which data is stored on remote servers accessed from the internet, or "cloud." It is maintained, operated and managed by a cloud storage service provider on storage servers that are built on virtualization techniques.

\section{Cloud Computing Service Models}

The essence of the concept of cloud computing is to provide end users with remote dynamic access to services, computing resources and applications which includes operating systems and infrastructure over the Internet. Aharony (2015) stated cloud computing can be divided into three different service models which are:

Software as a Service (SaaS) can be referred as a subscription based model where third-party provider hosts the applications and makes them available to customers over the internet. SaaS has changed the concept of software as a product to that of a service instead. Most well-known examples are Netflix and Office 365.

Platform as a Service (PaaS) is a complete development and deployment environment in the cloud of which a third-party provider delivers hardware and software tools as PaaS include infrastructure, storage, networking, development tools, and database management systems. In a simpler term, PaaS enables powerful tools for developers to create the applications, without having to deal with concerns about the infrastructure.

Infrastructure as a Service (laaS) is an instant computing infrastructure that provides virtualised computing resources and it is provisioned and managed over the Internet as laaS provides complete infrastructure resources such as servers, software, network equipment and storage. laaS helps avoiding the expense and complexity of buying and managing physical servers and datacentre infrastructure.

\section{Cloud Computing Deployment Models}

There are four different types of deployment models of which is a specific type of cloud environment, primarily distinguished by ownership, size and access (Mell and Grance, 2011).

Private cloud - usually runs within the organization to keep all their records safe. The cloud infrastructure is supplied exclusively for a single organization comprising multiple consumers. Community cloud - supplied exclusively for a specific community of consumers from organizations that has shared concerns.

Public cloud - have an open access feature and open use for the general public. It existed on the premises of the cloud provider.

Hybrid cloud - encompasses two or more cloud models that remain unique entities but are bound together by standardized technology that enables data and application portability.

\section{Benefits of Adopting Cloud Computing}

Many businesses are starting to move their business to the cloud as it benefits them in many ways. There are several benefits that could encourage more businesses to adopt cloud computing. 


\section{Flexibility}

Ul Haq Quddusi (2014) suggest that by using cloud computing, people are able to use the software however they like and whenever required, which are ideal for businesses with fluctuating or shrinking bandwidth demand.

\section{Reducing the expense cost}

The ability to turn the substantial in advance IT investment into operational expenses, the ability to reduce IT management, operational and maintenance cost and lower data centre's cost variability to get ready for the unpredictable and changing demands (Phaphoom, Wang \& Abrahamsson, 2013) is a lucrative advantage to have. Cloud computing cuts out the high cost of hardware and cheaper for user as they do not have to buy software as cloud computing apply the concept "pay for only what you use".

\section{Competitive advantage}

It allows smaller businesses to compete with the big company with pay-as-you-go service where they could disrupt the market while remain lean and nimble.

\section{Data security}

Other than data being stored in the cloud which reduce damage if user's computer was damaged, the deployment of encryption, VLANs and Firewalls could be an enticing prospect (Armbrust et al., 2010).

\section{Increase collaboration}

Cloud-based workflow and file sharing apps helps them make updates in real time and gives them full visibility of their collaborations (UI Haq Quddusi, 2014).

\section{Better document control}

All files are stored centrally and allows more efficient computing benefiting from centralizing storage, memory, processing and bandwidth along with improve efficiency in organization's way of work (Khajeh-Hosseini et al., 2011).

\section{Environmentally friendly}

Cloud computing provides organization to go for paperless environment within the organization.

\section{Factors that Influence IP to Adopt Cloud Computing}

There are several factors that would influence the adoption of cloud computing among IP. The aforementioned factors could be either supportive or concerning. Those factors are relative advantage, security concerns and top manager support.

\section{Relative advantage}

Rogers Everett (1995) defines it as the degree to which new technology is perceived as change for the better than the assurance it supersedes. Mohammed, Ibrahim and Ithnin (2016) defined 
Vol. 7, No. 3, July 2018, E-ISSN: 2226-6348 @ 2018 HRMARS

relative advantage as degree to which the decision makers understand that cloud being better than other computing paradigms. It is been mentioned by Aharony (2014) that if information organizations directors would like to encourage their employees to use the technological innovations such as cloud computing, they should present their employees its ease of use and emphasize cloud computing's advantages.

\section{Top management support}

Gutierrez, Boukrami and Lumsden (2015) opines that top management support is extraordinarily critical for companies looking to create a competitive environment while also imparting the precise resources which consist of technical know-how and infrastructure required adopting cloud services. Having this assist aids organisations in overcoming any internal obstacles and resistance to change. It's been recognized that top management recognition of the potential advantages of adopting cloud computing is important to control ability organisational change via an expressed vision and commitment, sending effective indicators of confidence within the new era to all employees of the company.

\section{Trialability factor}

"Trialability of an innovation will lead to an increase in the rate of adoption" (Lin \& Chen, 2012). Trialability can be described in the context of cloud computing as a services experimentation on a limited basis by the potential adopters (Rogers Everett, 1995). From the use of cloud services in daily life, users become aware of the emergence of cloud computing and its benefits. It is just a matter of their acceptance of changing their way of work to accommodate the integration of cloud computing.

\section{Storage factor}

Cloud storage is a subcategory of the cloud computing where it enables users to store and retrieve data on the servers anywhere at any time. Cloud storage continuous security, easy access, low cost of ownership and scalability is the biggest encouragement for cloud storage adoption (Comsa, 2011) with scalability as the most enticing prospect about this adoption because of its ability to expand to meet future needs.

\section{Security}

The ability to prevent unauthorized access or modification to information in storage, processing or transit. Regarding cloud computing technology, data security and privacy are the major concerns for adoption (Lian, Yen and Wang, 2014). For organization, IP need to consider the security of cloud service in order to secure organization's confidential documents as cyberattacks occurrences have been rampant with the likes of the famous iCloud hacks to the most latest Equifax cyber-attack scandal. Thus, the security and privacy of information held in cloud computing environments is one of the most significant concerns.

\section{Compatibility}

Lin and Chen (2012) suggested compatibility and loss of governance could be another factors that influence the adoption of cloud computing. Compatibility can be defined as consistency between a previously mooted idea and the perceived innovation. Rogers Everett (1995) stated that rate of 
Vol. 7, No. 3, July 2018, E-ISSN: 2226-6348 @ 2018 HRMARS

adoption increase and uncertainty decrease when an innovation is more compatible with the existing values, past experiences and needs of potential adopters which show how compatibility is a major concern. The lack of standardization of application program interfaces and platform technologies could pose a problem for the adoption of cloud computing as interoperability between platforms can be poor and companies would not be able to transfer easily from one cloud provider to another. This perceived lack of control could discourage organization to adopt cloud computing.

\section{Conclusion}

Cloud computing can be the future and it may become the next platform for building innovation ecosystem for the development of economic and social infrastructure. Organizations will always try to find alternative ways or new innovative ways of work to be step ahead of their competitors and cloud computing could be one of the ways. Cloud computing can be encouraging for IP to adopt as it can benefits the organization in many ways. Top management support is another mean for the adoption of cloud computing that could encourage IP to adopt but they will need some convincing in order for them to try and adopt cloud computing. Security concern and compatibility issue are major concerns for organizations to adopt cloud computing. The technology is still growing and innovating to move forward and tackle every concern organizations have on cloud computing but cloud computing is still relatively new and immature for organizations to use in project development as it is too risky. These factors could sway the decision to influence the IP to adopt cloud computing.

\section{References}

Aharony, N. (2014). Cloud computing: information professionals' and educational technology experts' perspectives. Library Hi Tech, 32(4), 645-666.

Aharony, N. (2015). An exploratory study on factors affecting the adoption of cloud computing by information professionals. Electronic Library, 33(2), 308-323.

Armbrust, M., Fox, A., Griffith, R., Joseph, A. D., Katz, R., Konwinski, A., ... Zaharia, M. (2010). A View of Cloud Computing. Commun. ACM, 53(4), 50-58. http://doi.org/10.1145/1721654.1721672

Bruneo, D., Distefano, S., Longo, F., Puliafito, A., \& Scarpa, M. (2013). Workload-based software rejuvenation in cloud systems. IEEE Transactions on Computers, 62(6), 1072-1085.

Buyya, R., Yeo, C. S., \& Venugopal, S. (2008). Market-Oriented Cloud Computing: Vision, Hype, and Reality for Delivering IT Services as Computing Utilities. In 2008 10th IEEE International Conference on High Performance Computing and Communications (pp. 5-13). http://doi.org/10.1109/HPCC.2008.172

Comsa, G. (2011). An Intro to Cloud Storage for Business-A few reasons cloud storage is a musthave tool for all businesses today. Cloud Computing Journal.

Davis, F. D. (1989). Perceived Usefulness, Perceived Ease of Use, and User Acceptance of Information Technology TT -. MIS Quarterly TA -, 13(3), 319-340.

Ercan, T. (2010). Effective use of cloud computing in educational institutions. Procedia - Social and Behavioral Sciences, 2(2), 938-942.

Farber, D. (2008). The new geek chic: Data centers. Retrieved from http://news.cnet.com/830113953_3-9977049-80.html 
INTERNATIONAL JOURNAL OF ACADEMIC RESEARCH IN PROGRESSIVE EDUCATION AND DEVELOPMENT

Vol. 7, No. 3, July 2018, E-ISSN: 2226-6348 @ 2018 HRMARS

Goscinski, A., \& Brock, M. (2010). Toward dynamic and attribute based publication, discovery and selection for cloud computing. Future Generation Computer Systems, 26(7), 947-970.

Gutierrez, A., Boukrami, E., \& Lumsden, R. (2015). Technological, organisational and environmental factors influencing managers' decision to adopt cloud computing in the UK. Journal of Enterprise Information Management, 28(6), 788-807.

He, Q., Han, J., Yang, Y., Jin, H., Schneider, J.-G., \& Versteeg, S. (2014). Formulating costeffective monitoring strategies for service-based systems. IEEE Transactions on Software Engineering, 40(5), 461-482.

Katsaros, G., Kousiouris, G., Gogouvitis, S. V, Kyriazis, D., Menychtas, A., \& Varvarigou, T. (2012). A Self-adaptive hierarchical monitoring mechanism for Clouds. Journal of Systems and Software, 85(5), 1029-1041. http://doi.org/https://doi.org/10.1016/j.jss.2011.11.1043

Khajeh-Hosseini, A., Sommerville, I., Bogaerts, J., \& Teregowda, P. (2011). Decision support tools for cloud migration in the enterprise. In Cloud Computing (CLOUD), 2011 IEEE International Conference on (pp. 541-548). IEEE.

Lian, J.-W., Yen, D. C., \& Wang, Y.-T. (2014). An exploratory study to understand the critical factors affecting the decision to adopt cloud computing in Taiwan hospital TT -. International Journal of Information Management, 34(1), 28-36.

Lin, A., \& Chen, N.-C. (2012). Cloud computing as an innovation: Percepetion, attitude, and adoption. International Journal of Information Management, 32(6), 533-540. http://doi.org/https://doi.org/10.1016/j.ijinfomgt.2012.04.001

Mao, M., \& Humphrey, M. (2012). A performance study on the vm startup time in the cloud. In Cloud Computing (CLOUD), 2012 IEEE 5th International Conference on (pp. 423-430). IEEE.

Mell, P., \& Grance, T. (2011). The NIST definition of cloud computing. Gaithersburg, MD : Computer Security Division, Information Technology Laboratory, National Institute of Standards and Technology,. Retrieved from http://purl.fdlp.gov/GPO/gpo17628

Mohammed, F., Ibrahim, O., \& Ithnin, N. (2016). Factors influencing cloud computing adoption for e-government implementation in developing countries. Journal of Systems and Information Technology, 18(3), 297-327.

Pan, M.-J., \& Jang, W.-Y. (2008). Determinants of the adoption of enterprise resource planning within the technology-organization-environment framework: Taiwan's communications industry. Journal of Computer Information Systems, 48(3), 94-102.

Phaphoom, N., Wang, X., \& Abrahamsson, P. (2013). Towards a Conceptual Framework for Assessing the Benefits of Cloud Computing BT - Software Business. From Physical Products to Software Services and Solutions: 4th International Conference, ICSOB 2013, Potsdam, Germany, June 11-14, 2013. Proceedings. In G. Herzwurm \& T. Margaria (Eds.), (pp. 141152). Berlin, Heidelberg: Springer Berlin Heidelberg. http://doi.org/10.1007/978-3-64239336-5_14

Rogers Everett, M. (1995). Diffusion of innovations. New York, 12.

Sultan, N. (2010). Cloud computing for education: A new dawn? International Journal of Information Management, 30(2), 109-116.

UI Haq Quddusi, S. (2014). Document management and cloud computing. The TQM Journal, 26(2), 102-108. 